\title{
Modelling of an Electrohydraulic Proportional Valve with a Synchronous Motor
}

\author{
Andrzej Milecki* - Dominik Rybarczyk \\ Poznan University of Technology, Institute of Mechanical Technology, Poland
}

This paper presents the design of proportional valve with a Permanent Magnet Synchronous Motor (PMSM). The proposed valve is described, and its history is briefly reviewed. Basic equations describing the valve are formulated and its simulation model is implemented in MATLABSimulink software. Selected nonlinearities are included in this model. In order to determine the basic parameters of the discussed proportional valve, a test stand is built, which enables valve investigations. In this test stand, a valve control system based on programmable logic controller $(P L C)$ with a touch panel and inverter module is implemented and used for investigations. The valve flow characteristics and step responses obtained in simulations are presented. These characteristics are compared with results obtained in experimental investigations. As a result, the valve simulation model is modified and improved.

Keywords: proportional valve, electrohydraulic, synchronous motor

Highlights

- Proposing a new type of hydraulic proportional valve in which the synchronous motor is used.

- $\quad$ Proposing a theoretical description and simulation model of the valve with a synchronous motor.

- $\quad$ Presenting the proposed laboratory investigation results of the valve.

- Improving the simulation model of the valve based on the outcomes of the investigations.

\section{O INTRODUCTION}

Electrohydraulic servo-drives can be controlled by two types of electro-valves: servo- and proportional valves. The servo-valves are used in high-accuracy applications. Proportional valves respond acceptably to the requirements stated in most industrial cases and are much cheaper than servo-valves. Therefore, these elements are commonly used in many industrial electrohydraulic drives. Proportional valves are activated by solenoids and can provide a smooth and continuous variation in flow or pressure in response to an electrical input valve. The basics of the design of proportional valves were established approximately 30 years ago and no significant progress in this area has been visible since then [1] and [2]. Many investigations and related publications about electrohydraulic servo drives have been focused on the improvement of the properties of these drives, via the implementation of modern forms and types of control [3]. Only a few works deal with improvements of the parameters of electrohydraulic drive elements, as well as with finding new ways to provide very accurate movement of valve parts, such as a valve's spool. Thus far, in proportional valves, proportional electromagnets are commonly used as the slider driving part [4]. Only in a few solutions can stepping or DC motors be found, even though they have been known for many years. Based on that, we decided to apply a new type of drive device, a permanent magnet synchronous motor (PMSM) as electromechanical actuator in the proportional valve (this motor is characterized by very good properties and can assure very good positioning accuracy).

Over the previous decade, only a few papers focused on the applications of different types of motors in hydraulic proportional valves have been published. Murrenhoff [5] described the cross-cutting trends in the design and the development of electrohydraulic valves. He presented an interesting solution, using the direct drive in a proportional valve. In another solution, the use of a stepping motor to transfer the ball screw, which was moving the mechanism with four independent flow sliders, was proposed. The design and investigations of valve in which a piezo actuator was used were described in [6]. Such a valve is characterized by very good dynamic parameters in comparison with valves controlled by proportional electromagnets.

Boes at al. [7] pointed out the advantages of valves with integrated control electronics. The use of powerful processors and a decentralized control system allowed the easy integration of electrohydraulic valve with other elements.

Myszkowski and Milecki [8] described the use of a stepping motor in the valve to obtain a very low velocity of the electrohydraulic drive. It is worth emphasizing that the drive was able to move with a very low constant speed equal to $1 \mathrm{~mm} / \mathrm{s}$. However, the drive maximum speed was only $0.125 \mathrm{~mm} / \mathrm{s}$, 
which was rather low and reduced the number of possible applications.

In another study [9], an unconventional electrohydraulic proportional flow control valve based on a switching solenoid and a fuzzy-logic controller was proposed. The switching solenoid's non-linear force/ stroke characteristic was linearized by a fuzzy-logic controller. The obtained laboratory investigations of this valve were quite satisfactory, assuring low cost.

Šimic et al. [10] presented a new approach to the modelling and simulation of hydraulic spool valves by using simple mathematical expressions to describe the geometry of the sliding spool metering edge. Consequently, different shapes of spool-metering edges in combination with other functional elements could be used in design of hydraulic valves.

The literature overview has shown that only in one paper [11] was the use of an electric servo motor for control of the proportional valve described. However, this solution was significantly different from commonly used designs. The servo-motor that was used in a valve was able to produce torque of as much as $15 \mathrm{Nm}$. The cam mechanism used allowed the motor shaft to move in the range of only a few degrees of arc. The maximum valve flow was as much as $400 \mathrm{dm}^{3} / \mathrm{min}$; therefore that valve was much bigger than the one considered in this paper.

\section{VALVE CONSTRUCTION}

The schematic of the valve proposed in this paper is presented in Fig. 1. The valve spool (3) is actuated by a permanent magnet synchronous motor (1). In the proposed valve the motor type 8LVA22 (B\&R company) is used. Its basic parameters are power $105 \mathrm{~W}$, current $2.9 \mathrm{~A}$, nominal torque: $0.65 \mathrm{Nm}$. This motor is connected to the spool (3) by a flexible bellows coupling (2). The second ending of the spool is directly connected to a ball screw (5), whose nut (6) is fixed to the valve body. The rotation of the motor causes the rotation of the ball screw and the axial movement of the spool and its control edges. This movement is proportional to the angular motor displacement and the pitch of the thread used. The direction of rotation determines the direction of spool translation and the opening or closing of valve gaps. It results in the flow of oil to and from the actuator chambers and the displacement of the piston. The spool diameter is $10 \mathrm{~mm}$. There are three rectangular gaps in the body with dimensions of $2.5 \mathrm{~mm} \times 2 \mathrm{~mm}$. The valve size is 10 (below $64 \mathrm{dm}^{3} / \mathrm{min}$ ).

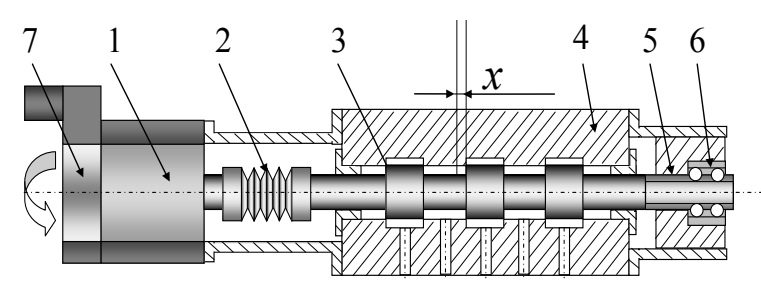

Fig. 1. Scheme of proportional valve with synchronous motor

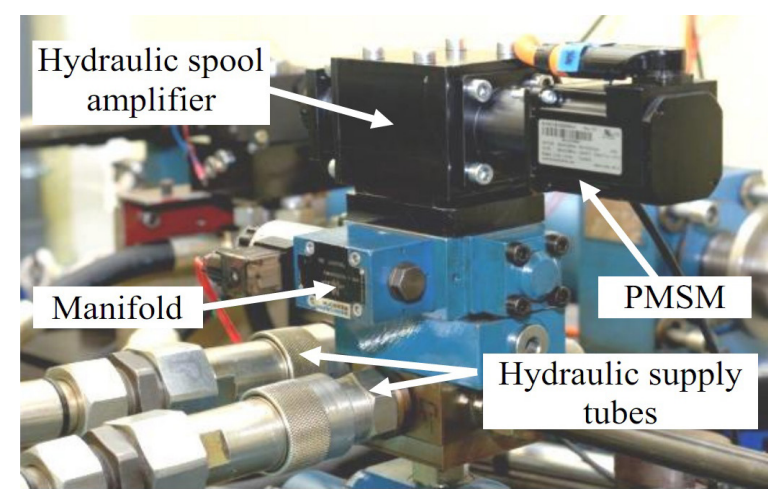

Fig. 2. View of proportional valve with PMSM

The rotor position is measured by an absolute encoder type EnDat 2.2 (7), providing a current position, even after a power failure, with a very high positioning accuracy, equal to 262144 pulses on revolution. As a result, the drive is able to assure the linear resolution of $0.5 \mathrm{~mm}$ [12] and [13]. The photo of the valve is presented in Fig. 2. The valve is connected to the cylinder by a specially designed manifold.

\section{VALVE MODELING AND BASIC INVESTIGATIONS}

In order to investigate the designed and built valve, a test stand was arranged. Its schematic diagram is presented in Fig. 3. A valve control system is based on PLC working under a real time operating system Automation Runtime with a Power Panel 500 touch panel and ACOPOS servo-controller used for PMSM control [14]. A HySense QG100 flow meter is used, whose parameters are max. flow $Q=30 \mathrm{dm}^{3} / \mathrm{min}$, max. pressure $p=30 \mathrm{MPa}$, non-linearity $\pm 0.5 \%$, 1640 pulses per $\mathrm{dm}^{3}$. It is connected to the counter module in the PLC unit. As a communication interface between the PLC and the servo controller, a Powerlink interface is used. The view of the control system is shown in Fig. 4. In the synchronous motor controller, two feedback loops are used. The inner one is a velocity feedback in which a $\mathrm{P}$ type regulator is used. The second one is the positioning loop with a PI regulator. Their parameters are set using autotuning mode, based on the detection of one or two points of the process frequency response using relay excitation 
described by Åström and Hägglund [15]. The following values of parameters are used: $k v=0.41 / \mathrm{s}$ for the velocity loop and $k_{P}=220$, integrative time $T_{i}=0.0004 \mathrm{~s}$ for positioning loop.

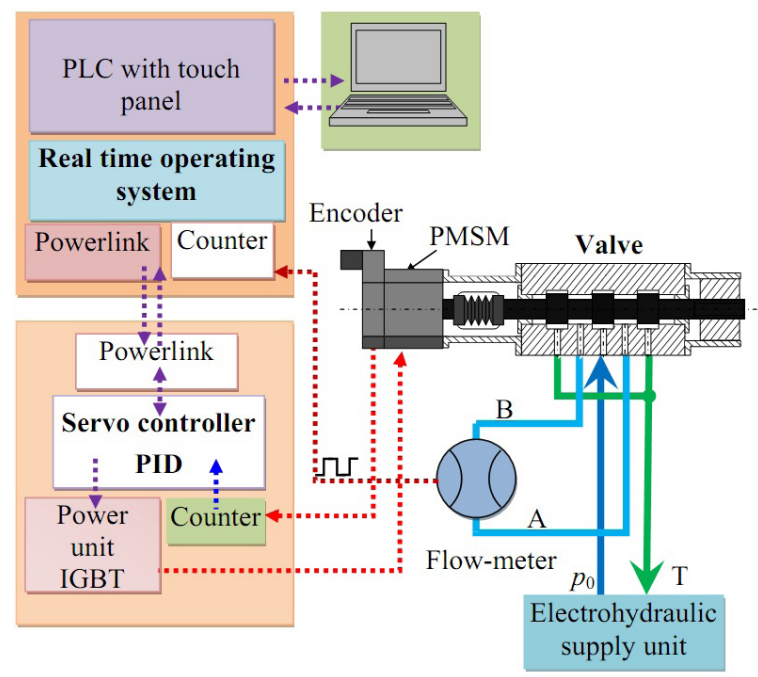

Fig. 3. The scheme of control stand

The valve flow through the sharp-edged nozzles is turbulent [2] and [9], which can be described using the following general equation:

$$
Q=K_{Q} \sqrt{\Delta p} \cdot x,
$$

where $K_{Q}$ is a flow coefficient, $\Delta p$ pressure drop on a valve, and $x$ a spool displacement $( \pm 2.5 \mathrm{~mm})$.

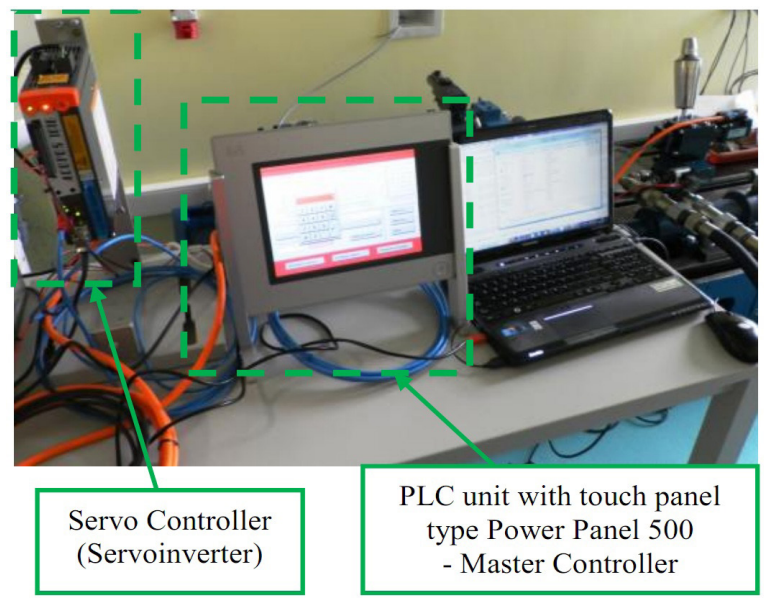

Fig. 4. A view of proportional valve with a synchronous motor

The flow coefficient $K_{Q}$ depends on the following parameters:

$$
K_{Q}=\mu_{d} \cdot \sqrt{2 / \rho} \cdot w
$$

where $\mu_{d}$ is the discharge coefficient, $\rho$ oil density: $780 \mathrm{dm}^{3} / \mathrm{min}, w$ width of the gap $(6 \mathrm{~mm})$.

The value of the discharge coefficient $\mu_{d}$ depends mainly on the geometry of the slot. In the case of the proportional valve considered in this paper, this value is usually taken as 0.64 [2]. Using Eq. (1), the theoretical calculations of valve flow $Q$ for spool displacements in a range of $\pm 2.5 \mathrm{~mm}$ and for pressures $4 \mathrm{MPa}, 6 \mathrm{MPa}, 12 \mathrm{MPa}$ and $14 \mathrm{MPa}$ are made and shown in Fig. 5. In order to verify these calculations, the real valve is investigated. A flow $Q$ changes for two supply pressures, $6 \mathrm{MPa}$ and $12 \mathrm{MPa}$, are measured. Due to the applied flow meter, it was possible to measure flow only until $30 \mathrm{dm}^{3} / \mathrm{min}$. It can be noted that the characteristics of a real valve are curved when the input signal increases. Most probably, this is caused by the valve spool's non-symmetry. In the test stand (Fig. 3), both gaps are connected serially. If one of these gaps is smaller than the other, the pressure drop on the first one is bigger. As a result, the flow saturation occurs in this gap, which is determined by pressure square root characteristic, described by Eq. (1). This is visible in the presented laboratory results.

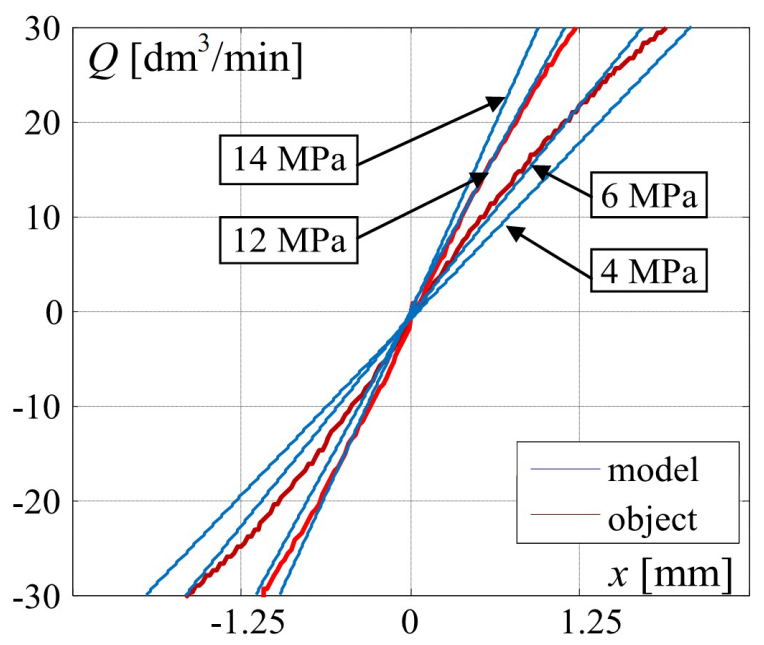

Fig. 5. The flow characteristics

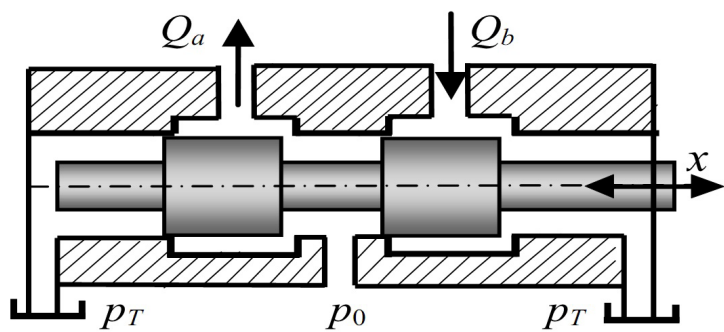

Fig. 6. A four-edge hydraulic amplifier

The hydraulic part of proportional valve is a fouredge amplifier, shown in Fig. 6. Its static behaviours 
can be characterized using so-called square root equations, which describe the oil flow through the hydraulic nozzles. These flows can be described by following equations:

$$
\begin{array}{ll}
\text { for } x>0: & \begin{array}{l}
Q_{a}(t)=K_{Q} \sqrt{p_{0}-p_{a}(t)} \cdot x(t) \\
\\
Q_{b}(t)=K_{Q} \sqrt{p_{b}(t)} \cdot x(t)
\end{array} \\
\text { for } x<0: & \begin{array}{l}
Q_{a}(t)=K_{Q} \sqrt{p_{a}(t)} \cdot x(t) \\
Q_{b}(t)=K_{Q} \sqrt{p_{0}-p_{b}(t)} \cdot x(t)
\end{array}
\end{array}
$$

where $x$ is a spool displacement $[\mathrm{mm}], Q_{a}$ flow through the gap A [ $\left.\mathrm{dm}^{3} / \mathrm{min}\right], Q_{b}$ flow through the gap B $\left[\mathrm{dm}^{3} / \mathrm{min}\right], K_{Q}$ flow coefficient, $p_{0}$ supply pressure $[\mathrm{Pa}]$, and $p_{a}, p_{b}$ pressures in chambers $\mathrm{A}$ and $\mathrm{B}[\mathrm{Pa}]$.

The spool dynamics can be described by the following PMSM motion equation:

$$
m \frac{d^{2} x(t)}{d t}+D \frac{d x(t)}{d t}=\frac{2 \pi}{P} K_{T} i(t)=K_{i} i(t),
$$

where $m$ is the mass reduced in motor axis $(0.2 \mathrm{~kg}), D$ viscous friction coefficient $(120 \mathrm{Ns} / \mathrm{m}), P$ ball screw pitch $\left(2.5 \mathrm{~mm} / \mathrm{rev}\right.$.), $T$ PMS motor torque, $K_{T}$ torque coefficient $(0.23 \mathrm{Nm} / \mathrm{A})$.

In the first approach, the electric circuit of PMS motor is described by the second order transfer function:

$$
L \frac{d i(t)}{d t}+R i(t)=U(t)
$$

where $L$ is $4.1 \mathrm{mH}, R=2 \mathrm{Ohm}$ coil inductance and resistance, $i$ current, $U$ supply voltage.

After the Laplace transformation of Eqs. (5) and (6), and their combination we obtain:

$$
X(s)=\frac{K_{T} / D}{T_{1} s^{2}+s} \cdot \frac{1 / R}{T_{2} s+1} U(s) .
$$

The drive transfer function is as follows:

$$
G(s)=\frac{X(s)}{U(s)}=\frac{k_{d}}{s\left(T_{1} s+1\right)\left(T_{2} s+1\right)},
$$

where $T_{1}=m / D$ and $T_{2}=L / R$ are time constants.

Using Eqs. (3), (4) and (7), a simulation model of the proportional valve with PMSM is prepared in Matlab-Simulink software (Fig. 7). It includes square root flow non-linearity, which is modelled using the function Sqrt. A simplified model of the PMSM is also included. The rotor position and the valve spool position are simultaneously measured by element characterized by coefficient $k_{m}$ and fed back to the PI type, position controller. The measured position is derived in order to obtain a velocity signal, used in inner feedback loop.

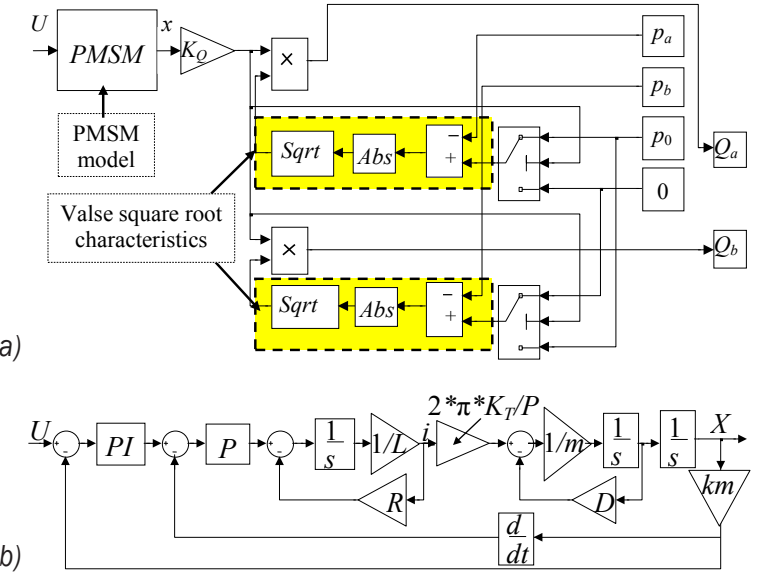

Fig. 7. Matlab-Simulink simulation models of the: a) valve, b) PMSM (simplified)

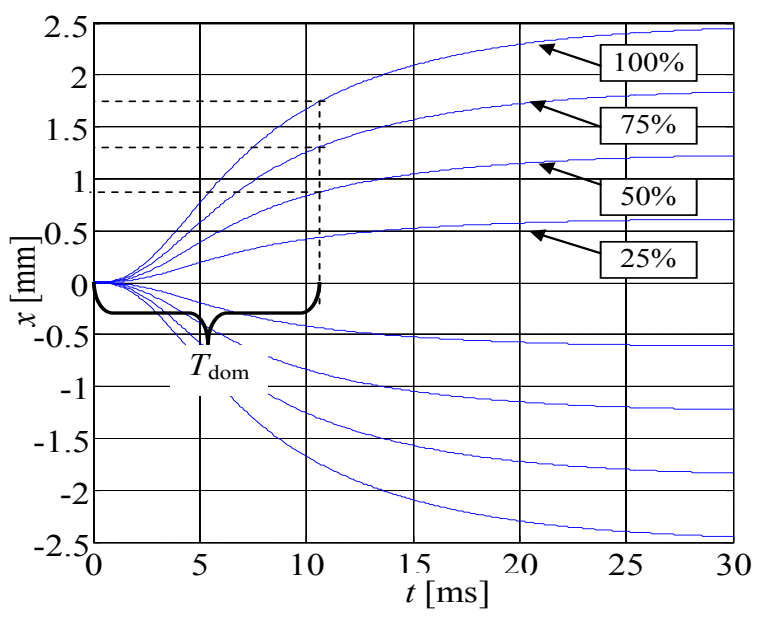

Fig. 8. The step responses of the valve spool

The valve step responses obtained by simulation (spool displacement $x$ ) are shown in Fig. 8. The time constant $T_{\text {dom }}$, which represents the time it takes the system's step to reach 0.63 of its final value, is equal to about $11 \mathrm{~ms}$.

\section{MODEL IMPROVEMENT}

In order to verify the correctness of the proposed simulation model, the real valve step responses are measured. The results are shown in Fig. 9. The recorded curves indicate that the valve is characterized by a significant time delay, which is caused by a PLC controller and communication interface, which is used to control the PMSM.

Curves collected during several experimental investigations showed that the delay time constant $T_{0}$ is equal to $10 \mathrm{~ms}$. This delay is included into the following transfer function: 


$$
G(s)=\frac{X(s)}{U(s)}=\frac{k_{d} \cdot e^{s \cdot T_{0}}}{\left(T_{1} \cdot s+1\right) \cdot\left(T_{2} \cdot s+1\right)} .
$$

In this transfer function, the transport delay $T_{0}$ and time constants $T_{1}$ and $T_{2}$ are used. The valve of dominant time constant $T_{\text {dom }}$ depends on the assumed step signal values and varies from 7 to $12 \mathrm{~ms}$ (Fig. 9). These changes are most probably caused by a maximum current limitation of the motor. This current saturation is included in the model, shown in Fig. 10.
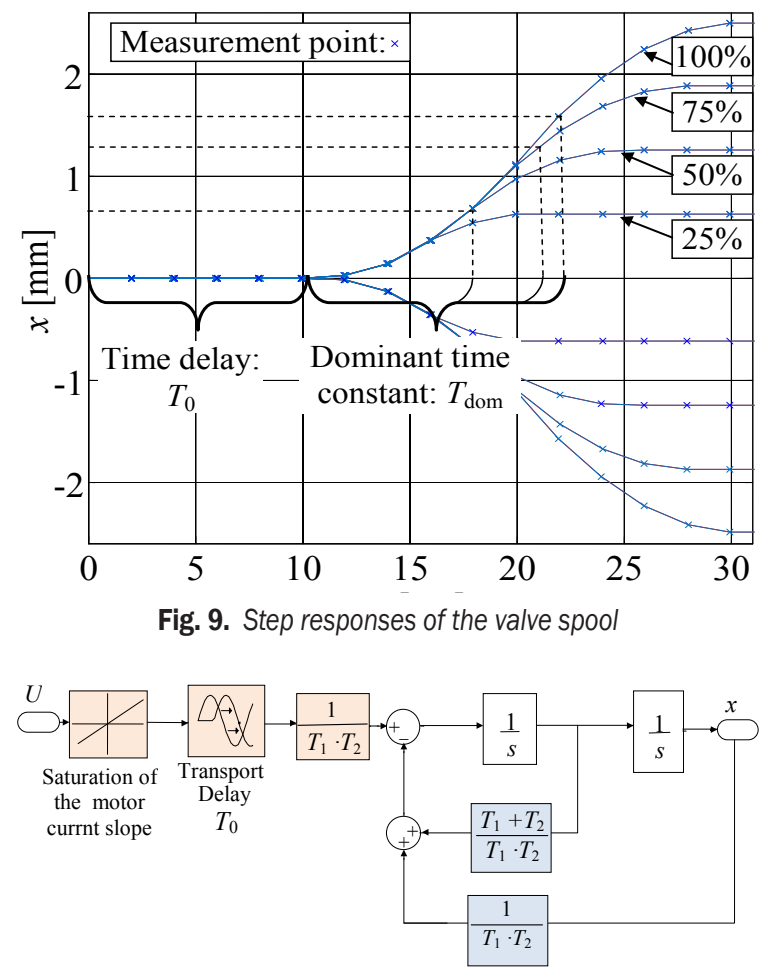

Fig. 10. Non-linear model of the PMS motor

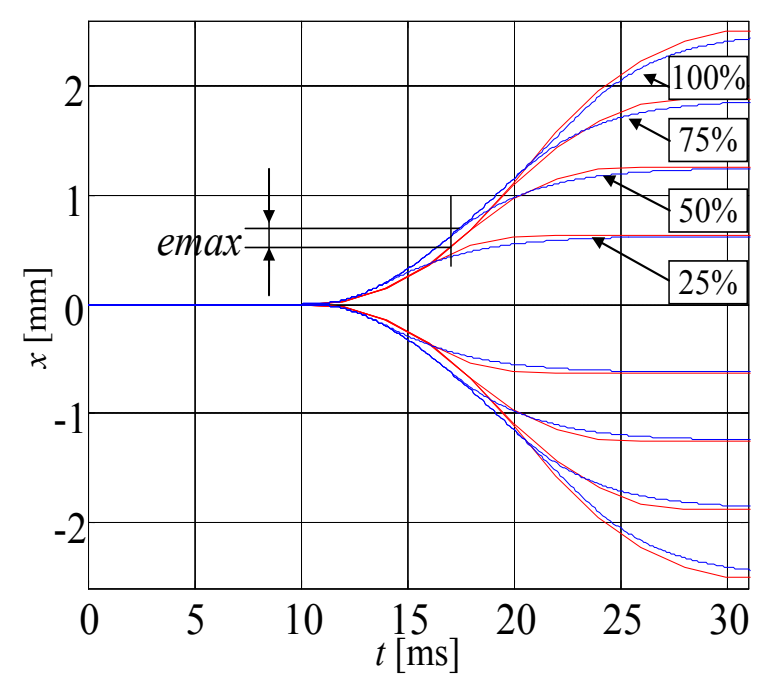

Fig. 11. The model and real valve step response
In Fig. 11, the step responses obtained in simulation with the use of model shown in Fig. 10 are presented. For comparison, curves obtained in experimental investigations are also shown in this figure. The maximum difference between the model and the real object curves emax is about $9 \%$. Consequently, one may conclude that the simulation results fit quite well with the results obtained in laboratory tests. The improved simulation model can then be regarded as suitable for the modelling and simulation of the proportional valve with PMSM drive.

\section{CONCLUSIONS}

In this paper, the theoretical description of a proportional valve with a PM synchronous motor is presented. Based on this description, a computer simulation model of a proposed valve with PMSM is proposed and implemented in MATLAB-Simulink software. This model is then compared with a real valve and improved. The study includes the laboratory examination of basic characteristics, such as valve flow and step response. The chosen simulation results are shown and discussed. The laboratory investigations of the proposed valve with PMSM are presented and compared with the simulation results. The simulation model proposed in the paper fits reflected the real situation very well.

The proportional valve with a permanent magnet synchronous motor that is presented in this paper represents an interesting alternative to servo-valves. It may assure better properties (especially dynamic and accuracy ones) than electrohydraulic standard proportional valves with solenoids do.

\section{ACKNOWLEDGMENT}

This paper was supported by the Polish Ministry of Science and Education, grant no. 02/23/DSPB/1208, Poland.

\section{REFERENCES}

[1] Chapple, P. (2003). Principles of Hydraulic System Design. Coxmoor Publishing Company, Oxford.

[2] Cundiff, S.J. (2000). Fluid Power Circuits and Control Fundamental and Applications. CRC Press, Boca Raton, London, New York, Washington.

[3] Ming, X., Jin, B., Chen, G., Ni, J. (2013). Speed-Control of Energy Regulation Based Variable-Speed Electrohydraulic Drive. Strojniški vestnik - Journal of Mechanical Engineering, vol. 59, no. 7-8, p. 433-442, D0l:10.5545/sv-jme.2012.911. 
[4] Muraru, V., Muraru, C. (2000). Optimization of the proportional solenoids for electrohydraulic control systems. Proceedings of the 1st FPNI-PhD Symposium, p. 157-166.

[5] Murrenhoff, H. (2003). Trends in valve development. Ölhydraulik und Pneumatik, vol. 46, no. 4, p. 1-36.

[6] Herakovič, N. (1995). Piezoactuator for a single-stage servovalve with high dynamic response (Piezoaktorbetatigung fur ein einstufiges hochdynamisches Servoventil), Olhydraulik \& Pneumatik, vol. 39, no. 8, p. 601-605. (in German)

[7] Boes, Ch., Lenz, W., Mueller, J. (2003). Digital servo valves with fieldbus interface in closed loop applications. The $8^{\text {th }}$ Scandinavian International Conference on Fluid Power, Tampere.

[8] Myszkowski, A., Milecki, A. (2009). Modelling of electrohydraulic servo drive used in very low velocity applications. International Journal of Modelling, Identification and Control, vol. 7, no. 3, p. 246-254, D0l:10.1504/ IJMIC.2009.027211.

[9] Renn, J.C., Tsai, C. (2005). Development of an unconventional electro-hydraulic proportional valve with fuzzy-logic controller for hydraulic presses. The International Journal of Advanced
Manufacturing Technology, vol. 26, no. 1-2, p. 10-16, DOI:10.1007/s00170-003-1973-7.

[10] Šimic, M., Debevec, M., Herakovič, N. (2014). Modelling of hydraulic spool-valves with specially designed metering edges. Strojniški vestnik - Journal of Mechanical Engineering, vol. 60, no. 2, p. 77-83, D0l:10.5545/sv-jme.2013.1104.

[11] Wiegandt, W. (2010). Development of a servomotor driven proportional valve. $7^{\text {th }}$ International Fluid Conference, Aachen.

[12] Rybarczyk, D., Milecki, A. (2015). Modeling and control of proportional valve with synchronous motor. Solid State Phenomena, vol. 220-221, p. 457-462, Dol:10.4028/www. scientific.net/SSP.220-221.457.

[13] Sędziak D., Regulski R. (2015). Design and investigations into piezobender controlled servovalve. Solid State Phenomena, vol. 220-221, p. 520-526, D0l:10.4028/www.scientific.net/ SSP.220-221.520.

[14] B\&R, Motion control, from http://www.br-automation.com/engb/products/motion-control/, accessed on 2015-02-20.

[15] Åström K., Hägglund T. (1995). PID controllers: Theory, Design and Tuning. Instrument Society of America, Research Triangle Park. 